\title{
Anti-methanogenic effects of monensin in dairy and beef cattle: A meta-analysis
}

\author{
J. A. D. Ranga Niroshan Appuhamy, ${ }^{* 1}$ A. B. Strathe, ${ }^{*}$ S. Jayasundara, $†$ C. Wagner-Riddle,† J. Dijkstra, $\ddagger$ \\ J. France,§ and E. Kebreab* \\ ${ }^{*}$ Department of Animal Science, University of California, Davis 95616 \\ †School of Environmental Sciences, University of Guelph, Guelph, ON, Canada N1G 2W1 \\ $\ddagger$ Animal Nutrition Group, Wageningen University, PO Box 338, 6700 AH Wageningen, the Netherlands \\ $\S$ Department of Animal and Poultry Science, University of Guelph, Guelph, ON, Canada N1G 2W1
}

\section{ABSTRACT}

Monensin is a widely used feed additive with the potential to minimize methane $\left(\mathrm{CH}_{4}\right)$ emissions from cattle. Several studies have investigated the effects of monensin on $\mathrm{CH}_{4}$, but findings have been inconsistent. The objective of the present study was to conduct meta-analyses to quantitatively summarize the effect of monensin on $\mathrm{CH}_{4}$ production $(\mathrm{g} / \mathrm{d})$ and the percentage of dietary gross energy lost as $\mathrm{CH}_{4}\left(Y_{m}\right)$ in dairy cows and beef steers. Data from 22 controlled studies were used. Heterogeneity of the monensin effects were estimated using random effect models. Due to significant heterogeneity $(>68 \%)$ in both dairy and beef studies, the random effect models were then extended to mixed effect models by including fixed effects of DMI, dietary nutrient contents, monensin dose, and length of monensin treatment period. Monensin reduced $Y_{m}$ from 5.97 to $5.43 \%$ and diets with greater neutral detergent fiber contents $(\mathrm{g} / \mathrm{kg}$ of dry matter) tended to enhance the monensin effect on $\mathrm{CH}_{4}$ in beef steers. When adjusted for the neutral detergent fiber effect, monensin supplementation [average $32 \mathrm{mg} / \mathrm{kg}$ of dry matter intake (DMI)] reduced $\mathrm{CH}_{4}$ emissions from beef steers by 19 $\pm 4 \mathrm{~g} / \mathrm{d}$. Dietary ether extract content and DMI had a positive and a negative effect on monensin in dairy cows, respectively. When adjusted for these 2 effects in the final mixed-effect model, monensin feeding (average $21 \mathrm{mg} / \mathrm{kg}$ of DMI) was associated with a $6 \pm 3 \mathrm{~g} / \mathrm{d}$ reduction in $\mathrm{CH}_{4}$ emissions in dairy cows. When analyzed across dairy and beef cattle studies, DMI or monensin dose $(\mathrm{mg} / \mathrm{kg}$ of DMI) tended to decrease or increase the effect of monensin in reducing methane emissions, respectively. Methane mitigation effects of monensin in dairy cows $(-12 \pm 6 \mathrm{~g} / \mathrm{d})$ and beef steers $(-14 \pm 6 \mathrm{~g} / \mathrm{d})$ became similar when adjusted for the monensin dose differences between dairy cow and beef steer studies.

Received July 9, 2012.

Accepted March 28, 2013.

${ }^{1}$ Corresponding author: ranga.appuhamy@gmail.com
When adjusted for DMI differences, monensin reduced $Y_{m}$ in dairy cows $(-0.23 \pm 0.14)$ and beef steers $(-0.33$ $\pm 0.16)$. Monensin treatment period length did not significantly modify the monensin effects in dairy cow or beef steer studies. Overall, monensin had stronger antimethanogenic effects in beef steers than dairy cows, but the effects in dairy cows could potentially be improved by dietary composition modifications and increasing the monensin dose.

Key words: dairy and beef cattle, meta-analysis, methane, monensin

\section{INTRODUCTION}

Methane $\left(\mathrm{CH}_{4}\right)$ is a greenhouse gas with a global warming potential 25 times greater than $\mathrm{CO}_{2}$ over a 100-yr period (IPCC, 2007). Agriculture produces approximately $50 \%$ of overall anthropogenic $\mathrm{CH}_{4}$ emissions globally (IPCC, 2007), and the largest biogenic source of $\mathrm{CH}_{4}$ is enteric fermentation from ruminants (US EPA, 2006). Besides the environmental concerns, enteric $\mathrm{CH}_{4}$ production negatively affects energy efficiency in cattle. Up to $11 \%$ of gross energy (GE) in cattle feed can be lost via eructated $\mathrm{CH}_{4}$ (Moraes et al., 2012). Two mechanisms primarily control enteric methane production in cattle: (1) the amount of dietary carbohydrates fermented in the rumen and (2) stoichiometry of VFA produced in the rumen, which affects the hydrogen availability for methane production (Johnson and Johnson, 1995; Ellis et al. 2008). Factors influencing one or more of these mechanisms consequently affect methane losses from cattle.

Monensin is a carboxylic polyether ionophore, commonly used to improve efficiency of energy (Byers, 1980) and N utilization (Ruiz et al., 2001) in cattle. Feeding monensin also reduces morbidity and mortality among feedlot cattle by reducing the incidence of acute and subacute ruminal acidosis, bloat, and bovine emphysema (Callaway et al., 2003). The effect of monensin on energy efficiency is related to its ability to selectively 
inhibit gram-positive over gram-negative bacteria that reduce succinate to propionate (McGuffey et al., 2001). Increased propionate to acetate ratios (Rogers and Davis, 1982) and reduced numbers of protozoa-generating hydrogen (Russell, 1987) in the rumen have indicated the potential of using monensin as a $\mathrm{CH}_{4}$ mitigation strategy in ruminants, particularly in intensive systems (Beauchemin et al., 2008).

Several published studies have investigated the effects of monensin on $\mathrm{CH}_{4}$ production in cattle, but the results have been inconsistent. For example, Van Vugt et al. (2005) and Odongo et al. (2007) reported significant declines $(6.5-12 \%)$ in $\mathrm{CH}_{4}$ emissions from dairy cows fed diets supplemented with monensin, but Grainger et al. (2010) and Waghorn et al. (2008) did not find such an effect. Dry matter intake and the nutrient composition of experimental diets, monensin dose, and length of monensin treatment period may be able to explain most of the between-study variability in the monensin effect (Guan et al., 2006; Beauchemin et al., 2008; Ellis et al., 2012). Meta-analyses compare and combine treatment effects of individual studies (Viechtbauer, 2010) and can also be used to explore between-study variability or heterogeneity of the treatment effects (Duffield et al., 2008). The objective of this study was to conduct meta-analyses to quantitatively summarize the effects of monensin on $\mathrm{CH}_{4}$ production in dairy cows and beef steers while exploring the factors that significantly explain the heterogeneity.

\section{MATERIALS AND METHODS}

\section{Data Sources}

Literature searches of the Web of Science (Thomson Reuters Science, New York, NY) and CAB Direct (CAB International, Wallingford, UK) online databases were conducted using the combination of search terms "monensin", "methane", and "cattle", or "cow". The period covered was 1970 to 2011 . The search resulted in 123 references related to studies of monensin effects on enteric methane production and rumen fermentation in cattle. All 123 references were scrutinized by reading the abstract of each reference carefully. For inclusion in the database, the studies were required to include a control treatment group that did not receive monensin, to be conducted in vivo using cattle, and include measured $\mathrm{CH}_{4}$ production as an outcome. Of the 123 references, 82 were related to in vitro studies focusing on the monensin effect in rumen fermentation and 21 were review papers. These were excluded from the database. The remaining 20 papers related to in vivo studies involving dairy and beef cattle and were selected for the database. However, another 4 papers were discarded as they did not contain any measures of sample variance or information helpful in calculating it (i.e., test statistics and $P$-values). Two conference papers were discarded, as they were duplicate publications of the same study. Another paper was removed, as the experiments did not have a control treatment group. The final data set contained 22 studies from the remaining 13 papers. A summary description of the selected studies is given in Table 1 .

\section{Data Extraction and Calculations}

Mean $\mathrm{CH}_{4}$ production in control and monensin treatment groups was the response variable of primary interest. Additionally, the following variables were considered: (1) ingredient and nutrient composition of experimental diets, including GE, NDF and ADF, NFC, $\mathrm{CP}$, and ether extract (EE) contents; (2) measured or estimated (in grazing experiments) DMI; (3) milk production of dairy cows; (4) monensin dose; (5) duration of feeding monensin; and (6) number of animals in treatment and control groups and dispersion estimates ( $\mathrm{SE}$ or $\mathrm{SD}$ ) of the $\mathrm{CH}_{4}$ measurements. Any missing nutrient composition values of the experimental diet were calculated using the ingredient composition and nutritive value tables in NRC $(1996,2001)$. For studies repeatedly measuring $\mathrm{CH}_{4}$, only the last $\mathrm{CH}_{4}$ measurement and the respective treatment durations were used. For studies only reporting the least significant difference and associated $t$-statistics, the standard error of difference (SED) was calculated as SED $=\mathrm{LSD} / t$. When the number of observations of both control and monensin treatments were similar (which was the case in majority of the studies), the standard error was calculated as: $\mathrm{SE}=\mathrm{SED} / \sqrt{ } 2$. If $\mathrm{LSD}$ values were not reported, standard errors were calculated using treatment mean difference, $P$-value for the treatment mean difference, and the number of observations.

Methane production was reported in grams per day in the majority of the papers. In some papers, it was reported in liters per animal per day. The liters per day units were converted to grams per day assuming that a mole of $\mathrm{CH}_{4}$ weighing $16.0 \mathrm{~g}$ has a volume of 22.4 L. Besides $\mathrm{CH}_{4}$ production, we were also interested in the effect of monensin on the percentage of feed GE lost as $\mathrm{CH}_{4}\left(\boldsymbol{Y}_{m}\right)$. Mean $Y_{m}$ values were available in some papers (Thornton and Owens, 1981; Van Vugt et al., 2005; Waugh et al., 2005); for the others, $Y_{m}$ was calculated using data on GE content $(\mathrm{MJ} / \mathrm{kg}$ of $\mathrm{DM})$ in the diet, DMI, and $\mathrm{CH}_{4}$ production $(\mathrm{g} / \mathrm{d})$, along with the fact that combustion of $1 \mathrm{~g}$ of $\mathrm{CH}_{4}$ releases $55.6 \mathrm{~kJ}$ of energy. If diet GE content was not reported, it was calculated using Atwater energy equivalents of nutrients (Merrill and Watt, 1973). Standard errors for 


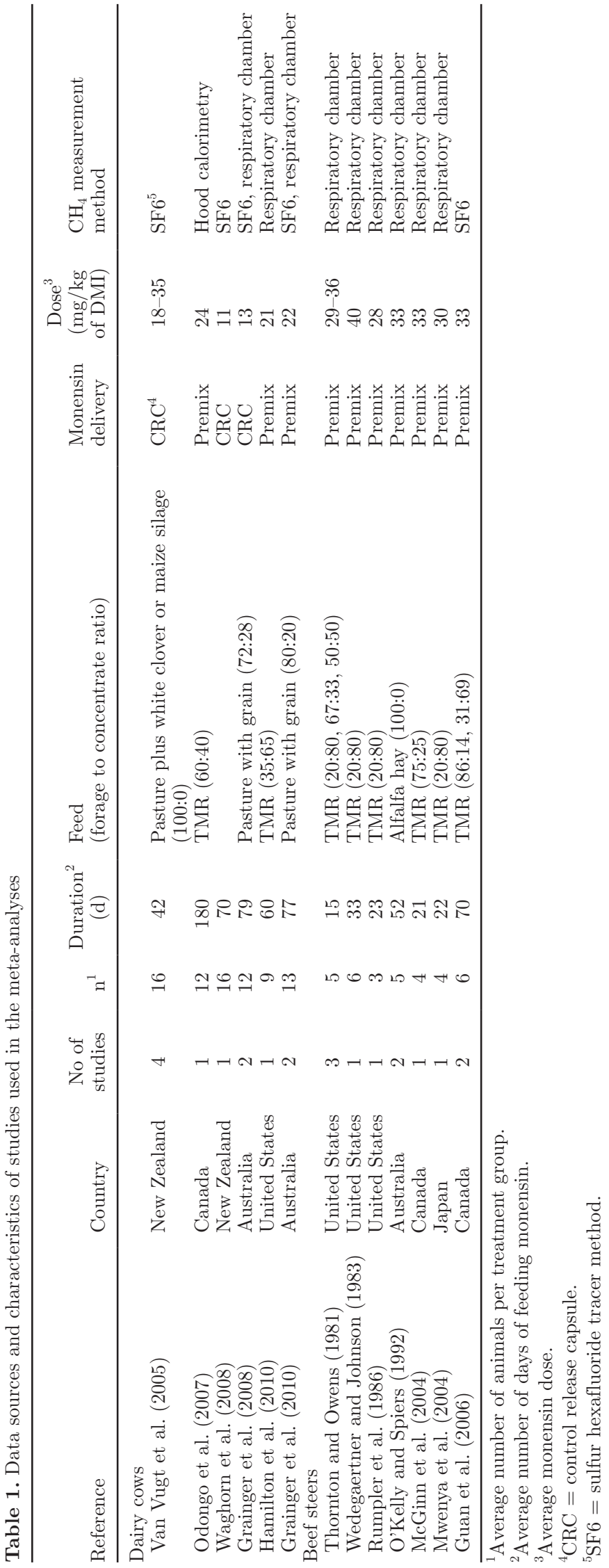

the calculated $Y_{m}$ were estimated using the mean difference $(\mathbf{M D} ; \mathrm{MD}=$ monensin treatment mean - control treatment mean), $P$-values of the corresponding $\mathrm{CH}_{4}$ production $\mathrm{MD}$, and the number of observations. As the DMI of each treatment group was not reported, $Y_{m}$ could not be calculated for the dairy cow grazing experiment in Grainger et al. (2008) and the beef steer trial in Rumpler et al. (1986).

\section{Statistical Analysis}

Separate meta-analyses were conducted for quantifying overall antimethanogenic effects of monensin in dairy cows, beef steers, and both dairy cows and beef steers using the metafor package (version 1.6-0) in $\mathrm{R}$ (version 2.12.2, R Foundation for Statistical Computing, Vienna, Austria). Moreover, the effects of monensin on DMI and milk production were also analyzed. Functions in the metafor package have been validated by comparing their results with those provided by other software packages, such as metan and metareg in Stata (StataCorp, College Station, TX) and the proc mixed command in SAS (SAS Institute Inc., Cary, NC), for several data sets (Viechtbauer, 2010).

Before beginning with the meta-analyses, effect size estimates and corresponding sampling variances were obtained. The MD and the standardized mean difference (SMD; SMD $=\mathrm{MD} /$ pooled SD of the 2 groups) are useful effect size measures for continuous response variables such as $\mathrm{CH}_{4}$ production. Standardized mean difference appropriately weights studies but is hard to interpret rationally because it is in SD units. On the other hand, MD allows effect size interpretation in the original units of the measurements. Also, considering the fact that the functions in the metafor package allow for weighting individual studies for corresponding sample variation (Viechtbauer, 2010), MD was used in meta-analysis models summarizing monensin effect size across all individual studies. Forest and funnel plots were constructed using SMD. The metafor package provides the escalc function for calculating various effect sizes including MD and SMD. It provides arguments for specifying data structure, treatment means, sampling error, sample size, and the preferred effect size measure. Relevant $\mathrm{R}$ codes are given in the appendix.

\section{Models}

We assumed that

$$
y_{i}=\theta_{i}+e_{i},
$$

where $y_{i}=$ the observed effect size or MD in the $i$ th study; $\theta_{i}=$ corresponding true effect size of the $i$ th 
study that is unknown; and $e_{i}=$ the sampling error $\left[e_{i} \sim N(0\right.$, sampling variance $\left.)\right]$ assumed to be known and taken as the squared standard error of the effect size. The sampling error remained fixed during estimation and, hence, served to weight the individual studies (Viechtbauer, 2010). Between-study variability (heterogeneity) of the true effects $\left(\theta_{i}\right)$ was also assumed to be purely random and this led to random-effect models given by

$$
\theta_{i}=\mu+u_{i}
$$

where $\theta_{i}=$ true effect size (MD) in the $i$ th study; $\mu=$ overall true effect size; and $u_{i}=$ random deviation from the overall effect size $\left[u_{\imath} \sim N\left(0, \tau^{2}\right)\right]$, which was unknown but estimated from data. The true effects were therefore normally distributed with mean $\mu$ and variance $\tau^{2}$. If $\tau^{2}=0$, it would imply homogeneity among true effects across individual studies so that $\mu=\theta$. Heterogeneity $\left(\tau^{2}\right)$ was expressed as a percentage of total variability $\left(\tau^{2}\right.$ plus sample variance) yielding $I^{2}$ statistics.

An $I^{2}$ value greater than $50 \%$ indicates considerable heterogeneity (Rabiee et al., 2010). Hence, for response variables with $I^{2}>50 \%$, the random-effect models were extended to mixed-models including fixed effects of variables having the potential to explain heterogeneity. These analyses are also called meta-regression analyses. The mixed-effect models were given by

$$
\theta_{i}=\beta_{0}+\beta_{1} x_{1 p}+\ldots \ldots+\beta_{p} x_{i p}+u_{i},
$$

where $\beta_{0}=$ overall true effect size; $x_{i j}=$ the value of the $j$ th explanatory variable $(j=1,2, \ldots, p)$ for the $i$ th study; and $\beta_{j}=$ change in the true effect size for unit increase in the $j$ th explanatory variable and again $u_{i} \sim N\left(0, \tau^{2}\right)$. Here, $\tau^{2}$ denoted the amount of residual heterogeneity, which was not described by the explanatory variables (Viechtbauer, 2010). We used DMI, monensin dose, monensin treatment duration, and dietary NDF, NFC, and EE contents as potential explanatory variables. Values of each explanatory variable were first centered on their means and then regressed individually against MD.

\section{Model Fitting and Model Selection}

The meta-analytic models were fitted using the rma function in the metafor package. The observed effect sizes and corresponding sampling variances calculated with the escalc function were respectively supplied via the $y i$ and $v i$ arguments in the rma function. The random-effect models were then fitted using the REML estimation method to estimate $\tau^{2}$. Moreover, the rma function estimates the $I^{2}$ statistics and tests statistical significance of $\tau^{2}$ using chi-squared tests (Higgins and Thompson, 2002). The mixed-effect models were constructed by including one or more explanatory variables using the mod argument in the rma function. Effects of the explanatory variables were estimated via weighted least squares with the weights $(w)$ equal to $w=1 /$ (sample variance + estimated $\tau^{2}$ ) (Viechtbauer, 2010). The metafor package does not provide functions for model selection. Hence, we first fitted models including individual explanatory variables. Full mixed-effect models carrying all explanatory variables having effects $(P<$ 0.10 ) when fitted individually were then fitted using the maximum likelihood (ML) method. Multi-collinearity was considered when selecting variables for the models. For example, monensin dose (mg/kg of DMI) and DMI were not analyzed together as they were highly correlated. Reduced models were formed via stepwise elimination of one variable at a time and fitted again with the ML method. The final mixed-effect models were chosen by testing reduced models versus full models using log-likelihood ratio tests. Furthermore, models with the same number of explanatory variables were compared using log-likelihood value, Akaike information criterion, and Bayesian information criterion given by the rma function. The parameter estimates of the final model were obtained by fitting the model using the REML method. Distinct sets of multivariate mixedeffect models were tested for the monensin effects separately for dairy cows and beef steers, or across both dairy cows and beef steers. When analyzed across dairy cow and beef steer studies, the explanatory variable effects on monensin were controlled for animal group variability by including it as a fixed categorical effect in the models. Publication bias of $\mathrm{CH}_{4}$ production measures in dairy cow or beef steer studies were assessed using Egger's regression test for funnel plot asymmetry (Viechtbauer, 2010).

\section{RESULTS AND DISCUSSION}

As Arnqvist and Wooster (1995) stated, any single study is worth little if not compared and related to other similar studies. Meta-analyses compare and combine findings from many related studies using statistical methods (Viechtbauer, 2010). The meta-analyses in this paper summarized the effects of monensin in both dairy cows and beef steers primarily related to $\mathrm{CH}_{4}$ production $(\mathrm{g} / \mathrm{d})$ and $Y_{m}(\%)$. Control and monensin treatment group means and standardized mean difference estimates of respective variables are presented in Figures 1 and 2 using forest plots. The monensin effects in dairy cows were notably inconsistent, as an almost equal number of studies had positive and nega- 
tive monensin effects on methane production (Figures $1 \mathrm{~A}$ and $2 \mathrm{~A}$ ). Monensin had a more consistent effect on $\mathrm{CH}_{4}$ mitigation in beef steers than dairy cows (Figures $1 \mathrm{~B}$ and $2 \mathrm{~B}$ ), but the effect sizes were still variable across studies. Dairy cow diets were supplemented with relatively low monensin doses (average $=21 \mathrm{mg} / \mathrm{kg}$ of DM) for a longer period of time compared with high monensin doses in beef steers (average $=32 \mathrm{mg} / \mathrm{kg}$ of DM) fed for relatively short periods (Table 1). The beef studies more consistently used monensin in premixes and the respiratory chamber method to measure $\mathrm{CH}_{4}$. Conversely, a considerable number of dairy studies used control release capsules to deliver monensin and the sulfur hexafluoride tracer method to measure $\mathrm{CH}_{4}$ (Table 1). Furthermore, nutrient compositions of the experimental diet were notably variable across both dairy and beef studies (Table 2).

\section{Effects of Monensin from Random Effect Models}

Meta-analyses using random effect models assume that the studies are a random sample of the entire population of studies so that any inference can be generalized beyond the studies included (Hedges and Vevea, 1998). At an average dose of $21 \mathrm{mg} / \mathrm{kg}$ of DM (Table 2 ), monensin did not significantly affect the amount of $\mathrm{CH}_{4}$ produced $(P=0.184)$ and $Y_{m}(P=0.471)$ in dairy cows (Table 3); in contrast, feeding monensin $32 \mathrm{mg} / \mathrm{kg}$ of DM, on average, substantially reduced $(P<0.001)$ $\mathrm{CH}_{4}$ production and $Y_{m}$ in beef steers by $19 \mathrm{~g} / \mathrm{d}$ and 0.54 percentage points, respectively. These values correspond to a 15 and $9 \%$ decline from the average $\mathrm{CH}_{4}$ production $(131 \mathrm{~g} / \mathrm{d})$ and $Y_{m}(5.97 \%)$ of steers that did not receive monensin, respectively (Table 3 ). The $\mathrm{CH}_{4}$ production decline could partially be explained by the reduced DMI $(-0.41 \mathrm{~kg} ; P=0.001)$ in beef steers. However, the significantly reduced $Y_{m}$, which was adjusted for the DMI difference, suggests a potential control of methanogenesis in the rumen by monensin. Sauer et al. (1998) observed significant declines in $\mathrm{CH}_{4}$ production $(17 \%)$ and ruminal acetate to propionate ratio $(19 \%)$ in dairy cows 2 wk after feeding monensin. Monensin also reduced DMI $(P<0.001)$ in dairy cows by $0.48 \mathrm{~kg} / \mathrm{d}$, representing a $2.6 \%$ decline from the average of cows in control group. Consistently, a meta-analysis by Duffield et al. (2008) revealed a $2.3 \%$ DMI decline $(P=0.001)$ among dairy cows for monensin supplementation. Their meta-analysis included 77 trials, only 2 of which were used in the current analyses. Although milk and milk solids yields $(\mathrm{kg} / \mathrm{d})$ were unaffected by monensin in the present study, Duffield et al. (2008) reported significant positive effects of monensin in dairy cows. The random effect models further quantified heterogeneity of monensin effects in terms of the $\tau^{2}$ and $I^{2}$ statistics. The effects of monensin were associated with significant $(P$ $<0.001$ ) between-study variability or heterogeneity in both dairy cows and beef steers (Table 3). More than $68 \%$ of the total variability of the monensin effects was due to heterogeneity in all cases $\left(I^{2}>68 \%\right)$.

Funnel plots were used to assess publication bias. Funnel plots in Figure 3A present SMD estimates of $\mathrm{CH}_{4}$ production on the horizontal axis and the corresponding standard error measures on the vertical axis. A middle vertical line is drawn at the summarized SMD with a confidence interval region (region between the dotted lines; Figure 3 ) given by $\pm 1.96 \mathrm{SE}$ (Viechtbauer, 2010). The funnel shape occurs as the larger and more precise studies tend to be closer to the expected effect, whereas the smaller, less precise studies are more variable. Funnel plot asymmetry is indicative of publication bias and can be assessed visually or by using a statistical test, such as Egger's regression test. The Egger's regression test revealed nonsignificant funnel plot asymmetry in beef steers $(P=0.098$; data not presented) indicating an absence of notable publication bias, but the funnel plot of dairy cows was significantly asymmetric $(P=0.008$; data not presented). Besides publication bias, funnel plot shape can vary due to several other factors, including heterogeneity (Terrin et al., 2005). Therefore, we continued with the dairy cow analysis based on an assumption that explaining heterogeneity with mixed-effect models would improve the funnel plot shape.

\section{Effects of Monensin and Explanatory Variables from Mixed Effect Models}

Level of feed intake, type of dietary carbohydrates, and dietary lipid contents generally influence methanogenesis in ruminants (Johnson and Johnson, 1995; Ellis et al., 2007; Beauchemin et al., 2008). Monensin dose (Beauchemin et al., 2008; Ellis et al., 2012), length of monensin treatment period, and dietary forage content (Guan et al., 2006; Odongo et al., 2007) have also been shown to influence effects of monensin on $\mathrm{CH}_{4}$ production in cattle. We chose DMI $(\mathrm{kg} / \mathrm{d})$ of control treatment, basal diet NDF, ADF, NFC, and EE contents $(\mathrm{g} / \mathrm{kg}$ of $\mathrm{DM})$, monensin dose $(\mathrm{mg} / \mathrm{kg}$ of $\mathrm{DMI})$, and length of monensin treatment period (d) as potential explanatory variables accounting for the heterogeneity associated with the monensin effects. The random effect models were extended to mixed effect models including the fixed effects of these factors. Before using in the mixed effect models, each explanatory variable was centered on its mean (Table 2). Such a rearrangement allows for interpreting the regression effects in terms of changes in a monensin effect size for a unit change in an explanatory variable from its mean. 


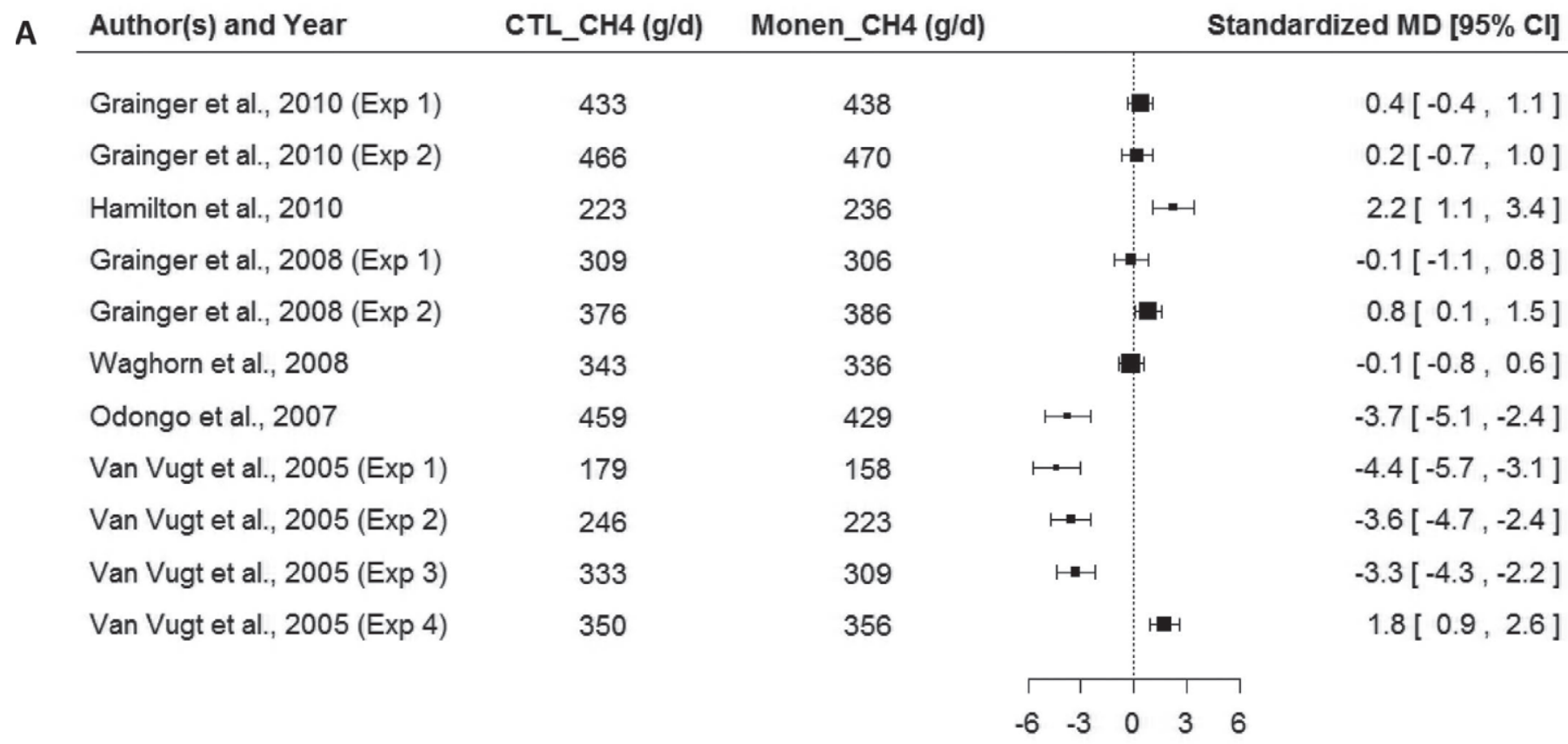

Standardized Mean Difference

B Author(s) and Year

CTL_CH4 (g/d) Monen_CH4 (g/d)

Standardized MD [95\% Cl]

Guan et al., 2006 (Exp 1)

196

171

Guan et al., 2006 (Exp 2)

214

164

Mwenya et al., 2004

70

58

McGinn et al., 2004

169

160

O'Kelly and Spiers., 1992 (Exp 1)

108

81

O'Kelly and Spiers., 1992 (Exp 2)

158

159

Rumpler et al., 1986

89

89

Wedegaertner and Johnson, 1983

103

76

Thornton and Owens, 1981 (Exp 1)

130

110

Thornton and Owens, 1981 (Exp 2)

173

132

Thornton and Owens, 1981 (Exp 3)

154

128

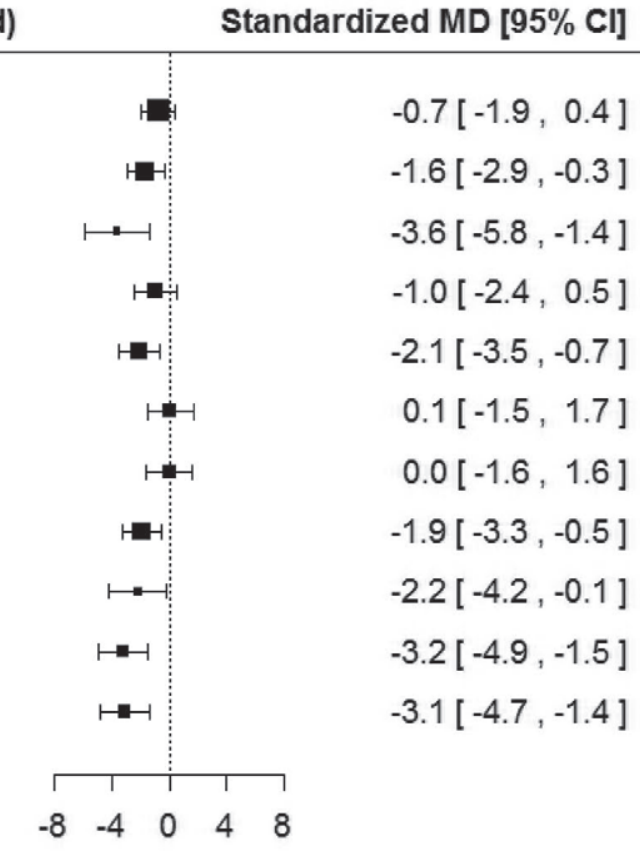

Standardized Mean Difference

Figure 1. Forest plot showing mean methane production (g/d) in control (CTL_CH4) and monensin treatment (Monen_CH4) groups along with standardized mean difference (MD) and its $95 \%$ CI for dairy cow (A) and beef steer (B) studies. The dotted line represents a 0 standardized mean difference.

Methane Production in Dairy Cows. The final mixed effect model for dairy cows included only DMI and dietary EE content, indicating significant independent effects on $\mathrm{CH}_{4}$ production (Table 4). The inter- cept of the model expresses the overall mean effect of monensin at mean DMI $(18.6 \mathrm{~kg} / \mathrm{d})$ and EE content $(38 \mathrm{~g} / \mathrm{kg}$ of DM). When adjusted for the DMI and EE effects, monensin showed a potential $(P=0.065)$ to 
Grainger et al., 2010 (Exp 1)

Grainger et al., 2010 (Exp 2)

Hamilton et al., 2010

Grainger et al., 2008 (Exp 1)

Waghorn et al., 2008

Odongo et al., 2007

Van Vugt et al., 2005 (Exp 1)

Van Vugt et al., 2005 (Exp 2)

Van Vugt et al., 2005 (Exp 3)

Van Vugt et al., 2005 (Exp 4)
6.1

7.3

2.5

5.5

6.3

7.3

5.2

8

5.5

6
6.3

7.6

2.7

5.4

6

7.1

4.6

7.7

5.3

6.4

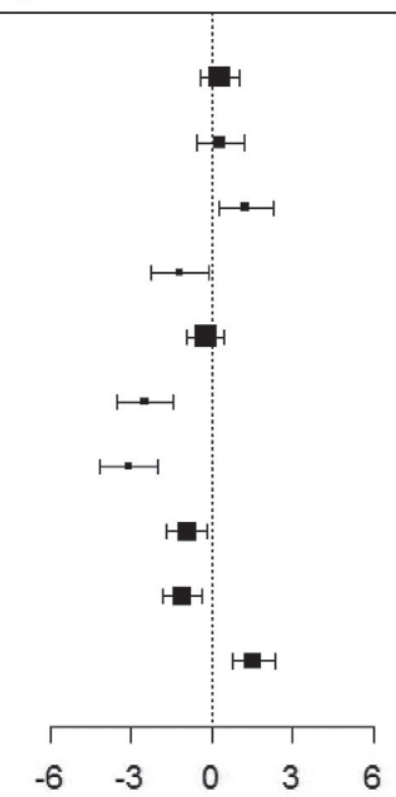

Standardized Mean Difference
$0.3[-0.4,1.0]$

$0.3[-0.6,1.2]$

$1.3[0.3,2.3]$

$-1.2[-2.3,-0.1]$

$-0.2[-0.9,0.5]$

$-2.5[-3.5,-1.4]$

$-3.1[-4.1,-2.0]$

$-0.9[-1.7,-0.2]$

$-1.1[-1.8,-0.3]$

$1.6[0.8,2.4]$

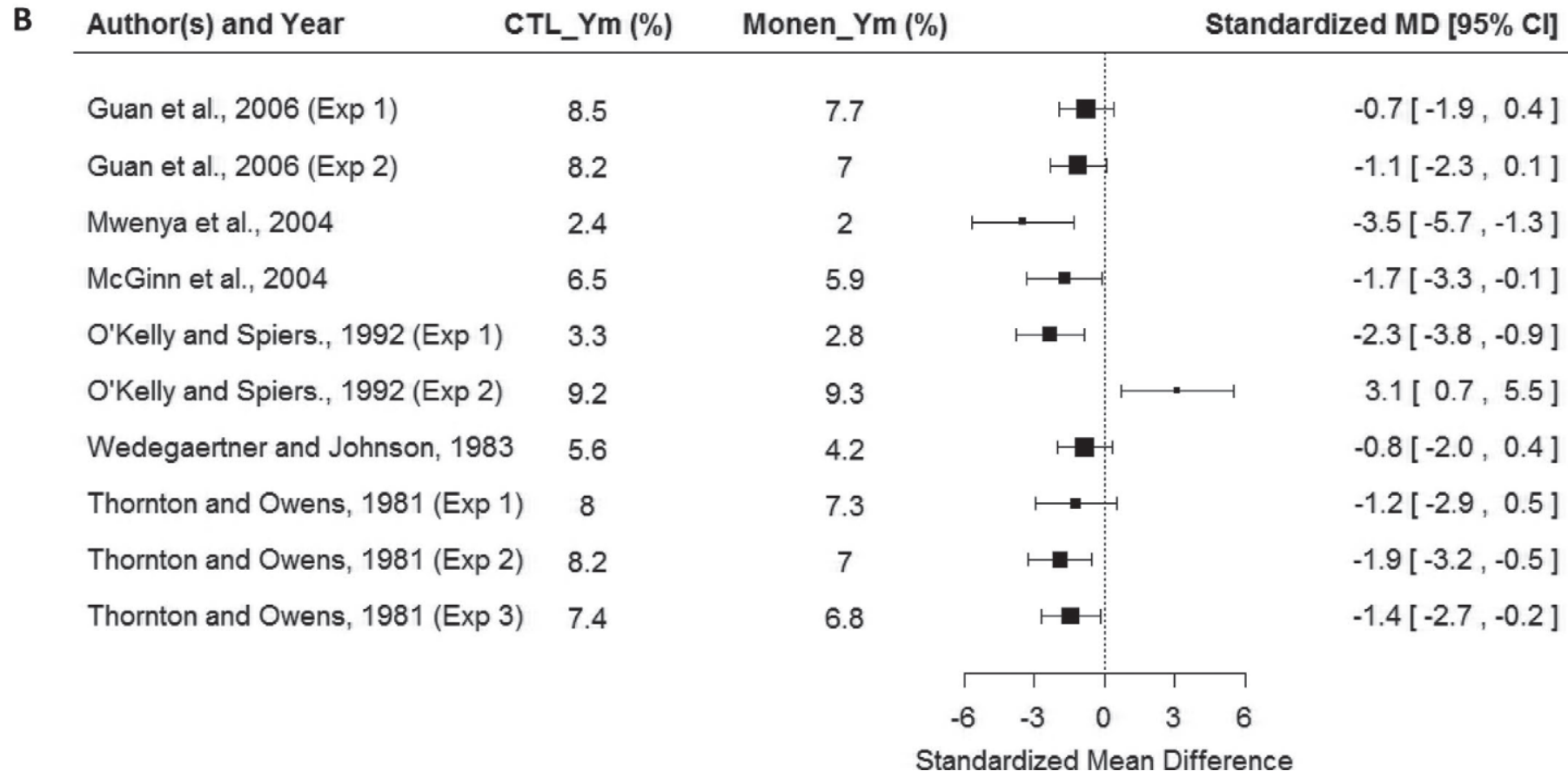

Figure 2. Forest plot showing mean dietary gross energy lost via $\mathrm{CH}_{4}\left(Y_{m}, \%\right)$ in control (CTL_Ym) and monensin treatment (Monen_Ym) groups along with standardized mean difference (MD) and its $95 \%$ CI for dairy cow (A) and beef steer (B) studies. The dotted line represents a 0 standardized mean difference.

reduce $\mathrm{CH}_{4}$ production in dairy cows by $6 \mathrm{~g} / \mathrm{d}$. A unit $(\mathrm{kg} / \mathrm{d})$ increase in DMI from its mean reduced $(P=$ $0.020)$ potential monensin-induced $\mathrm{CH}_{4}$ mitigation in dairy cows by $1.4 \mathrm{~g} / \mathrm{d}$. In contrast, a unit $(\mathrm{g} / \mathrm{kg}$ of
$\mathrm{DM}$ ) increase in dietary EE from its mean increased the monensin effect by $4.3 \mathrm{~g} / \mathrm{d}$. Addressing these effects reduced heterogeneity $\left(\tau^{2}=254 \pm 129\right.$ vs. $90.6 \pm$ 58.0) of $\mathrm{CH}_{4}$ production measures by $64 \%$ and thereby 
Table 2. Summary statistics for the explanatory variables

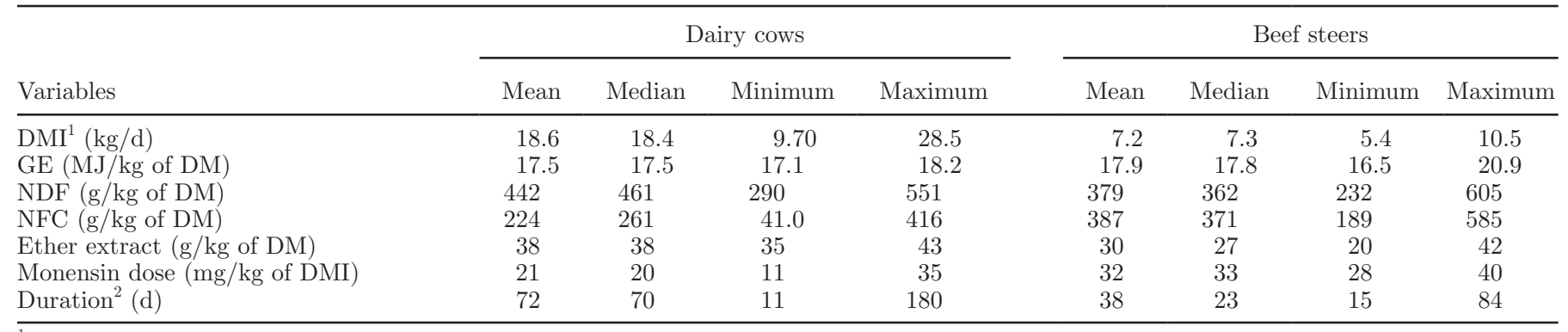

${ }^{1}$ Dry matter intake of the diet supplemented with monensin.

${ }^{2}$ Monensin feeding duration.

improved the funnel plot shape (Figure 3). An Egger's regression test revealed nonsignificant asymmetry $(P=$ 0.105) for the new funnel plot shape (Figure 3B).

Methane Production in Beef Steers. None of the explanatory variables except NDF had a tendency to affect the monensin effect on $\mathrm{CH}_{4}$ production in beef steers, so it was included in the final model (Table 4). Dietary NDF content explained $22 \%$ of the monensin effect heterogeneity. Feeding monensin in a diet with average NDF content (379 $\mathrm{g} / \mathrm{kg}$ of $\mathrm{DM})$ significantly $(P<0.001)$ reduced $\mathrm{CH}_{4}$ emissions from beef steers by $19 \mathrm{~g} / \mathrm{d}$. A unit increase in NDF content from its mean further increased monensin-induced $\mathrm{CH}_{4}$ mitigation by $0.05 \mathrm{~g} / \mathrm{d}(P=0.095)$. Nonetheless, the considerable residual heterogeneity (Table 4$)$ in both beef steers $\left(\tau^{2}=\right.$ $124 \pm 81.9)$ and dairy cows $\left(\tau^{2}=90.6 \pm 58.0\right)$ indicates that some variables other than the ones selected could further explain the variability of monensin effects on $\mathrm{CH}_{4}$ production.

$Y_{m}$ in Dairy Cows or Beef Steers. As with $\mathrm{CH}_{4}$ production, DMI was positively associated $(P=$
0.017) with the monensin effect on $Y_{m}$ in dairy cows (Table 4). When individually regressed, dietary NDF content tended $(P=0.091$; data not presented $)$ to have a negative effect on monensin in dairy cows, but the final mixed-effect model included only the DMI effect, suggesting confounded effects. The DMI alone considerably explained $(44 \% ; P=0.017)$ heterogeneity of monensin effect on $Y_{m}\left(\tau^{2}=0.09 \pm 0.05\right.$ vs. $0.05 \pm$ 0.04). None of the selected explanatory variables had a significant effect on the monensin effect on $Y_{m}$ in beef steers (Table 4).

Explanatory Variable Effects Across Dairy Cows and Beef Steers. With expectation of a more powerful inference on the explanatory variable effects, separate mixed effect model analyses were conducted using data from both dairy and beef trials. The random effect model analysis results revealed that monensin significantly $(P<0.001$; Table 3$)$ reduced $\mathrm{CH}_{4}$ emissions across dairy cows and beef steers. The final mixed effect models included only DMI or monensin dose effect. Because of a high correlation between DMI

Table 3. Number of studies used for the analyses (N), control group averages (Average), monensin effect size, and between-study variability estimates from random-effect models ${ }^{1}$

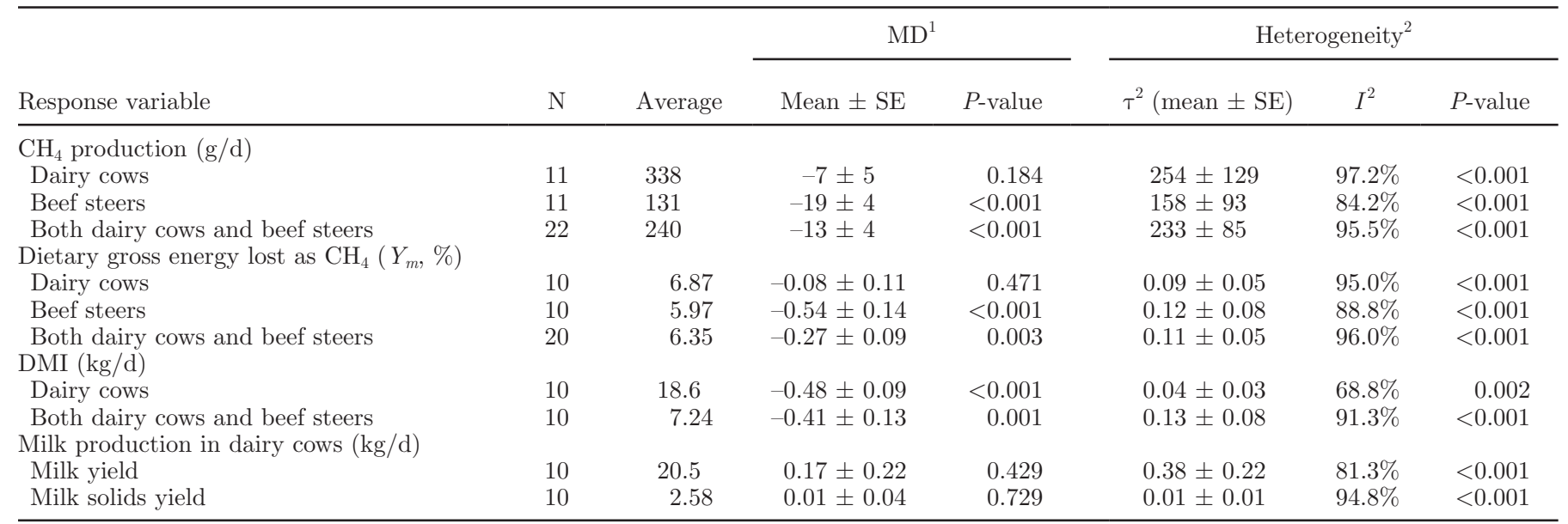

${ }^{1} \mathrm{MD}$ (mean difference) $=$ monensin treatment mean - control group mean.

${ }^{2} \tau^{2}=$ total amount of heterogeneity; $I^{2}=$ heterogeneity as a percentage of total variability. 
Table 4. Estimates of overall monensin effect (intercept), effects of explanatory variables, and total heterogeneity estimates $\left(\tau^{2}\right)$ from final mixed-effects models

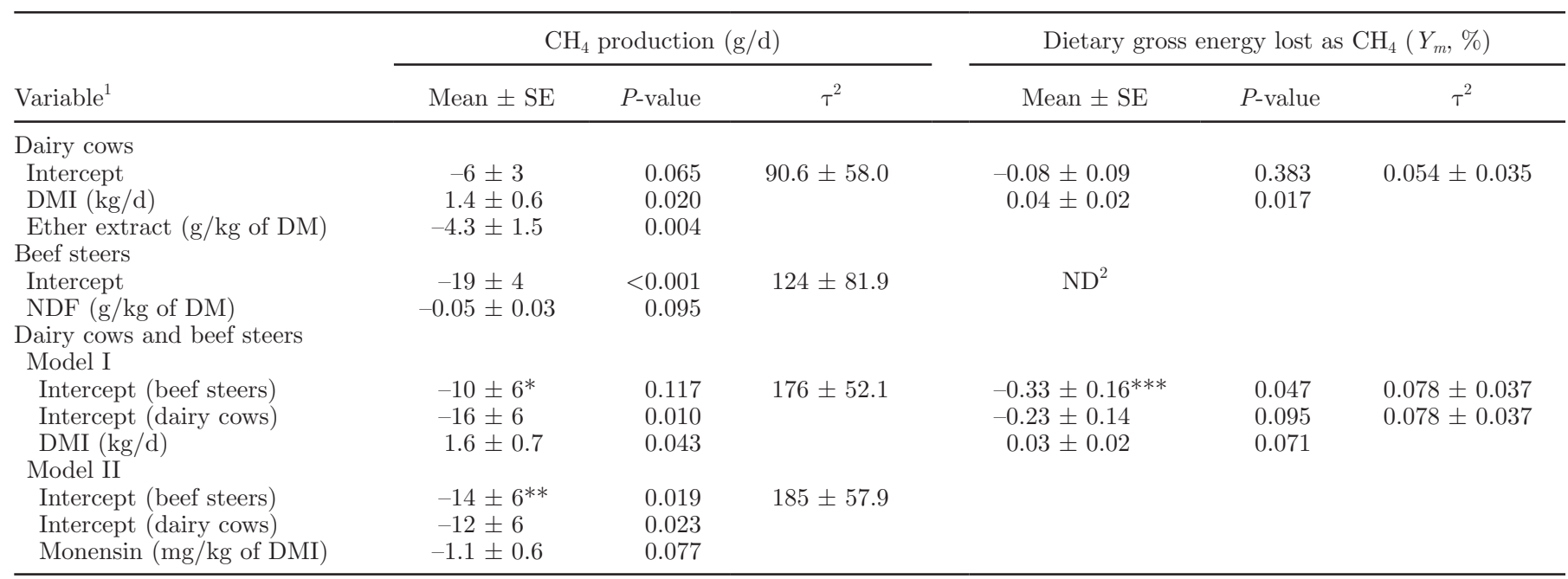

${ }^{1}$ The explanatory variables centered on the means.

${ }^{2}$ Not determined.

Intercepts were not different: ${ }^{*} P=0.592,{ }^{* *} P=0.880,{ }^{* * *} P=0.720$.

and monensin dose across dairy cows and beef steers ( $\mathrm{r}$ $=-0.77 ;$ data not presented), they were not assessed together due to multi-collinearity. Basal DMI and monensin dose reduced the heterogeneity of monensin effect on $\mathrm{CH}_{4}$ production by $25\left(\tau^{2}=176\right.$ vs. 233$)$ and
$21 \%\left(\tau^{2}=185\right.$ vs. 233$)$, respectively (Table 4$)$. A unit increase in DMI $(\mathrm{kg} / \mathrm{d})$ reduced the monensin effect on $\mathrm{CH}_{4}$ production by $1.6 \mathrm{~g} / \mathrm{d}(P=0.043)$, whereas a unit increase in monensin dose $(\mathrm{mg} / \mathrm{kg}$ of DMI) enhanced it by $1.1 \mathrm{~g} / \mathrm{d}(P=0.077$; Table 4$)$. Moreover, when
A

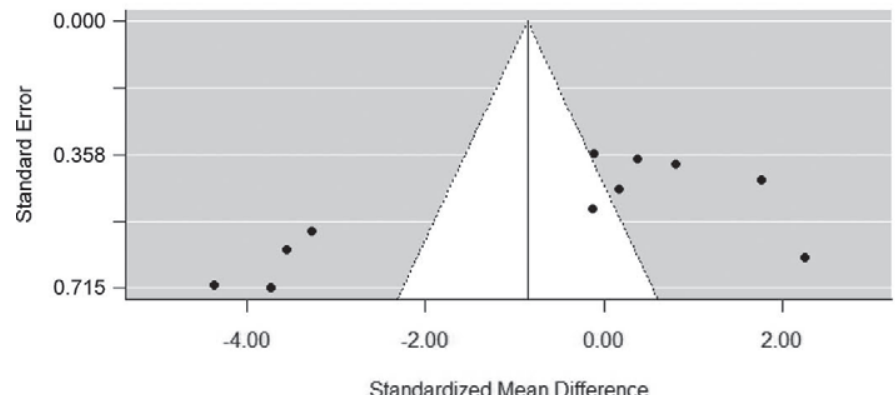

Beef steers

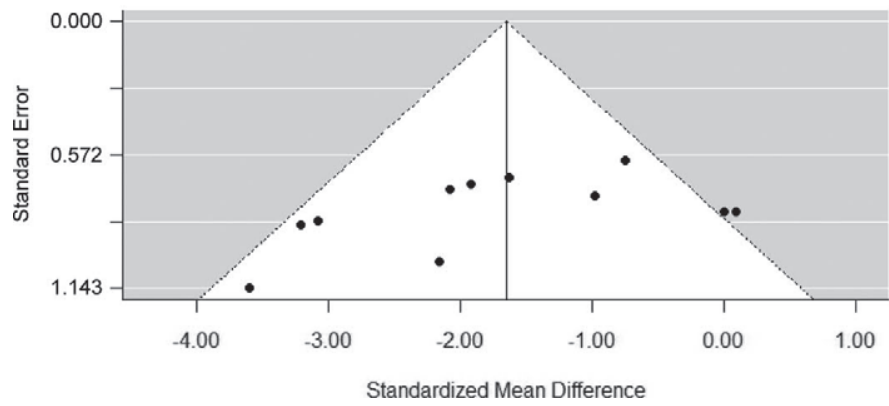

B

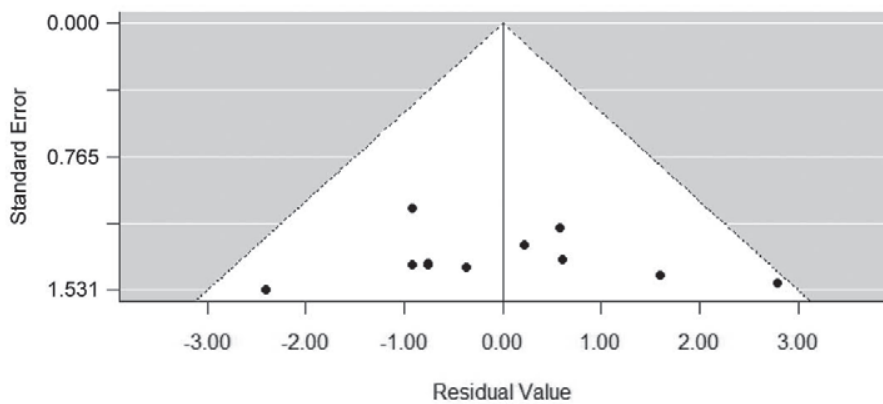

Beef steers

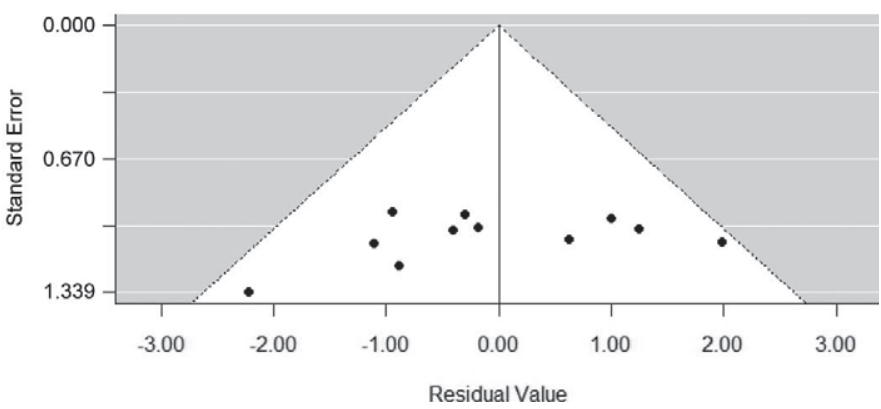

Figure 3. Funnel plots for monensin effect on $\mathrm{CH}_{4}$ production $(\mathrm{g} / \mathrm{d})$ in dairy cows and beef steers from random-effect models (A) and mixedeffect models (B). 
adjusted for basal DMI or monensin dose variability, effect sizes of monensin on $\mathrm{CH}_{4}$ production in dairy cows and beef steers were not significantly different from each other. Similarly, when adjusted for basal DMI differences, monensin effect sizes on $Y_{m}$ in dairy cows and beef steers were similar to each other. After adjusting for the dose differences, monensin feeding was associated with $14 \mathrm{~g} / \mathrm{d}(P=0.019)$ and $12 \mathrm{~g} / \mathrm{d}(P=$ $0.023)$ of $\mathrm{CH}_{4}$ production reductions in beef steers and dairy cows respectively (Table 4). These results indicate that the differential monensin effects observed between dairy cows and beef steers were partly due to monensin dose differences between the animal groups. A unit increase in monensin dose $(\mathrm{mg} / \mathrm{kg}$ of DMI) showed a potential $(P=0.077)$ to increase monensin-induced $\mathrm{CH}_{4}$ mitigation by $1.1 \mathrm{~g} / \mathrm{d}$ across dairy cows and beef steers. Moreover, the negative relationships between monensin dose and DMI (Table 5) suggest that the negative effect of increasing DMI on monensin effect could be related to an inadequate monensin supply $(\mathrm{mg} / \mathrm{d})$ to animals compared with their DMI. This inadequacy was more notable in dairy cows than beef steers. Average DMI of a dairy cow was almost 3 times greater than a beef steer (18.6 vs. $7.2 \mathrm{~kg} / \mathrm{d}$, respectively), but the cows were supplemented with less monensin compared with supplementation to beef steers (21 vs. $32 \mathrm{mg} / \mathrm{kg}$ of DMI, respectively).

Dietary ingredient and nutrient composition also appeared to modify the monensin effects on $\mathrm{CH}_{4}$. Dietary NDF content tended to enhance $(P=0.095)$ the $\mathrm{CH}_{4}$ mitigation effects of monensin in beef steers. Consistently, Thornton and Owens (1981) demonstrated greater $\mathrm{CH}_{4}$ mitigation by monensin in steers fed high-forage diets compared with those fed lowforage diets. Increasing dietary $\mathrm{EE}$ content increased the $\mathrm{CH}_{4}$ production $(\mathrm{g} / \mathrm{d})$ alleviation by monensin in dairy cows. Adding lipid to the diet generally reduced enteric methane emissions (Beauchemin et al., 2008). The mechanism through which lipid could specifically enhance monensin is not clear. Clary et al. (1993) and Mathew et al. (2011), who tested effects of dietary lipid on monensin, did not find any significant change in acetic to propionic ratios or protozoan numbers in the rumen in response to addition of lipid over monensin. However, drawing a sensible conclusion about the interaction between dietary lipid and monensin is difficult because half of the dairy cow studies were based on fresh forages (Table 1) and about half of the forage EE comprises undegradable cuticular waxes.

Persistency is an important requirement for any dietary strategy to be successful in mitigating $\mathrm{CH}_{4}$ emissions from ruminants (van Zijderveld et al., 2011). Findings related to the persistency of $\mathrm{CH}_{4}$ mitigation by monensin were inconsistent. Rumpler et al. (1986), Sauer et al. (1998), and Guan et al. (2006) showed that $\mathrm{CH}_{4}$ mitigation effects of monensin in cattle were short lived and would not last more than $30 \mathrm{~d}$. Conversely, Van Vugt et al. (2005), O'Kelly and Spiers (1992), and Odongo et al. (2007) found significantly reduced $\mathrm{CH}_{4}$ production from feeding monensin, even after $50 \mathrm{~d}$. Our results did not find a significant effect of monensin feeding duration (data not shown) on $\mathrm{CH}_{4}$ emissions in dairy cows $(P=0.678)$, beef steers $(P=0.646)$, or across both dairy cows and beef steers $(P=0.693)$. The $\mathrm{CH}_{4}$ mitigation effects of monensin in cattle therefore appeared to be fairly independent of how long monensin had been fed within the range included in the study (Table 2). Moreover, we tested the effects of $\mathrm{CH}_{4}$ measuring method (SF6 vs. chambers) on the monensin effect across dairy and beef studies and again did not find significant effects $(P=0.228$; data not presented).

In contrast to our results showing an effect of monensin on $Y_{m}$, which varies with diet composition and DMI, the IPCC (2007) tier 2 approach uses a fixed $Y_{m}$ (e.g., $6.5 \%$ of $\mathrm{GE}$ in dairy cows) in current inventories of enteric $\mathrm{CH}_{4}$ emissions. The IPCC tier 2 model does not have the capacity to fully describe changes in dietary composition and is limited in usefulness when estimating the effects of various nutritional strategies on $\mathrm{CH}_{4}$ emissions (Ellis et al., 2010). Given the significant effects of monensin on $Y_{m}$ and the modifying effect of various dietary characteristics on methane

Table 5. Correlation coefficients for relationships between DMI, gross energy (GE), NDF, NFC, and ether extract (EE) contents in diets, monensin dose, and length of monensin treatment period (Length) in dairy cows (above the diagonal) and beef steers (below the diagonal)

\begin{tabular}{|c|c|c|c|c|c|c|c|}
\hline Item & DMI & GE & NDF & NFC & $\mathrm{EE}$ & $\begin{array}{l}\text { Monensin } \\
\text { dose }\end{array}$ & Length \\
\hline DMI & & -0.29 & -0.72 & 0.86 & -0.22 & -0.44 & 0.23 \\
\hline GE & 0.18 & & -0.32 & -0.16 & 0.46 & -0.16 & -0.03 \\
\hline $\mathrm{NDF}$ & 0.04 & -0.41 & & -0.73 & -0.27 & 0.12 & -0.39 \\
\hline NFC & -0.13 & 0.27 & -0.96 & & -0.08 & 0.33 & 0.57 \\
\hline $\mathrm{EE}$ & -0.23 & 0.04 & -0.65 & 0.73 & & 0.39 & 0.41 \\
\hline Monensin dose & -0.41 & -0.03 & -0.28 & 0.22 & 0.31 & & -0.04 \\
\hline Length & 0.31 & -0.06 & -0.04 & -0.06 & -0.09 & 0.23 & \\
\hline
\end{tabular}


emissions, approaches other than IPCC tier 2 are required. Mechanistic models allow prediction of $\mathrm{CH}_{4}$ emissions in response to dietary changes that are more credible than empirical approaches, including the IPCC tier 2 method (e.g., Alemu et al., 2011). Recently, Ellis et al. (2012) developed equations to estimate the monensin dose-dependent change in VFA profile, and hence enteric $\mathrm{CH}_{4}$ production, in high-grain-fed beef cattle, and showed that monensin increased propionate and decreased acetate and butyrate molar proportions. Such equations combined with mechanistic models may help to better predict the $\mathrm{CH}_{4}$ mitigating effect of monensin in various dietary situations.

\section{CONCLUSIONS}

In summary, monensin reduced DMI in both dairy cows and beef steers but did not affect milk yield or milk solids yield in dairy cows. Monensin significantly reduced $(-19 \mathrm{~g} / \mathrm{d}) \mathrm{CH}_{4}$ emissions in beef steers but the effect $(-6 \mathrm{~g} / \mathrm{d})$ was marginal in dairy cows. Dry matter intake and dietary nutrient composition appeared to modify monensin effect on $\mathrm{CH}_{4}$. When adjusted for the differences in DMI or monensin dose between dairy cows and beef steer studies, monensin had similar and significant $\mathrm{CH}_{4}$ mitigation effects in both dairy cows and beef steers. Monensin supplemented at a higher rate (mg/cow per day), proportional to DMI, can potentially reduce $\mathrm{CH}_{4}$ emissions from dairy cows.

\section{ACKNOWLEDGMENTS}

Funding for this work was provided by the Dairy Farmers of Canada (Ottawa, ON), Canada Research Chairs Program (Ottawa, ON), and Sesnon Endowed Chair Program (UC Davis, CA).

\section{REFERENCES}

Alemu, A. W., J. Dijkstra, A. Bannink, J. France, and E. Kebreab. 2011. Rumen stoichiometric models and their contribution and challenges in predicting enteric methane production. Anim. Feed Sci. Technol. 166-167:761-778.

Arnqvist, G., and D. Wooster. 1995. Meta-analysis: Synthesizing research findings in ecology and evolution. Trends Ecol. Evol. 10:236-240.

Beauchemin, K. A., M. Kreuzer, F. O'Mara, and T. A. McAllister. 2008. Nutritional management for enteric methane abatement: A review. Aust. J. Exp. Agric. 48:21-27.

Byers, F. M. 1980. Determining effects of monensin on energy value of corn silage diets for beef cattle by linear or semi-log methods. J. Anim. Sci. 51:158-169.

Callaway, T. R., T. S. Edrington, J. L. Rychlik, K. J. Genovese, T. L. Poole, Y. S. Jung, K. M. Bischoff, R. C. Anderson, and D. J. Nisbet. 2003. Ionophores: Their use as ruminant growth promotants and impact on food safety. Curr. Issues Intest. Microbiol. 4:43-51.

Clary, E. M., R. T. Brandt Jr., D. L. Harmon, and T. G. Nagaraja. 1993. Supplemental fat and ionophores in finishing diets: Feedlot performance and ruminal digesta kinetics in steers. J. Anim. Sci. 71:3115-3123.

Duffield, T. F., A. R. Rabiee, and I. J. Lean. 2008. A meta-analysis of the impact of monensin in lactating dairy cattle. Part 3. Health and reproduction. J. Dairy Sci. 91:2328-2341.

Ellis, J. L., A. Bannink, J. France, E. Kebreab, and J. Dijkstra. 2010. Evaluation of enteric methane prediction equations for dairy cows used in whole farm models. Glob. Change Biol. 16:3246-3256.

Ellis, J. L., J. Dijkstra, A. Bannink, E. Kebreab, S. E. Hook, S. Archibeque, and J. France. 2012. Quantifying the effect of monensin dose on the rumen volatile fatty acid profile in high-grain fed beef cattle. J. Anim. Sci. 90:2717-2726.

Ellis, J. L., J. Dijkstra, E. Kebreab, A. Bannink, N. E. Odongo, B. W. McBride, and J. France. 2008. Aspects of rumen microbiology central to mechanistic modelling of methane production in cattle. J. Agric. Sci. 146:213-233.

Ellis, J. L., E. Kebreab, N. E. Odongo, B. W. McBride, E. K. Okine, and J. France. 2007. Prediction of methane production from dairy and beef cattle. J. Dairy Sci. 90:3456-3466.

Grainger, C., M. J. Auldist, T. Clarke, K. A. Beauchemin, S. M. McGinn, M. C. Hannah, R. J. Eckard, and L. B. Lowe. 2008. Use of monensin controlled-release capsules to reduce methane emissions and improve milk production of dairy cows offered pasture supplemented with grain. J. Dairy Sci. 91:1159-1165.

Grainger, C., R. Williams, R. J. Eckard, and M. C. Hannah. 2010. A high dose of monensin does not reduce methane emissions of dairy cows offered pasture supplemented with grain. J. Dairy Sci. 93:5300-5308.

Guan, H., K. M. Wittenberg, K. H. Ominski, and D. O. Krause. 2006. Efficacy of ionophores in cattle diets for mitigation of enteric methane. J. Anim. Sci. 84:1896-1906.

Hamilton, S. W., E. J. DePeters, J. A. McGarvey, J. Lathrop, and F. M. Mitloehner. 2010. Greenhouse gas, animal performance, and bacterial population structure responses to dietary monensin fed to dairy cows. J. Environ. Qual. 39:106-114.

Hedges, L. V., and J. L. Vevea. 1998. Fixed- and random-effects models in meta-analysis. Psychol. Methods 3:486-504.

Higgins, J. P., and S. G. Thompson. 2002. Quantifying heterogeneity in a meta-analysis. Stat. Med. 21:1539-1558.

IPCC. 2007. Climate Change 2007. S. Solomon, D. Quin, M. Manning, Z. Chen, M. Marquis, K. B. Averty, M. Tignor, and H. L. Miller, ed. Cambridge University Press, New York, NY.

Johnson, K. A., and D. E. Johnson. 1995. Methane emissions from cattle. J. Anim. Sci. 73:2483-2492.

Mathew, B., M. L. Eastridge, E. R. Oelker, J. L. Firkins, and S. K. Karnati. 2011. Interactions of monensin with dietary fat and carbohydrate components on ruminal fermentation and production responses by dairy cows. J. Dairy Sci. 94:396-409.

McGinn, S. M., K. A. Beauchemin, T. Coates, and D. Colombatto. 2004. Methane emissions from beef cattle: Effects of monensin, sunflower oil, enzymes, yeast, and fumaric acid. J. Anim. Sci. 82:3346-3356.

McGuffey, R. K., L. F. Richardson, and J. I. D. Wilkinson. 2001. Ionophores for dairy cattle: Current status and future outlook. J. Dairy Sci. 84(E. Suppl.):E194-E203.

Merrill, A. L., and B. K. Watt. 1973. Energy value of foods: Basis and derivation. Agriculture Handbook \#74. US Department of Agriculture, Agricultural Research Service, Washington, DC.

Moraes, L. E., J. E. Wilen, P. H. Robinson, and J. G. Fadel. 2012 A linear programming model to optimize diets in environmental policy scenarios. J. Dairy Sci. 95:1267-1282.

Mwenya, B., C. Sar, B. Santoso, T. Kobayashi, R. Morikawa, K. Takaura, K. Umetsu, S. Kogawa, K. Kimura, H. Mizukoshi, and J. Takahashi. 2004. Comparing the effects of 1-4 galactooligosaccharides and L-cysteine to monensin on energy and nitrogen utilization in steers fed a very high concentrate diet. Anim. Feed Sci. Technol. 118:19-30.

NRC. 1996. Nutrient Requirements of Beef Cattle. 7th rev. ed. National Academy Press, Washington, DC.

NRC. 2001. Nutrient Requirements of Dairy Cattle. 7th ed. National Academy Press, Washington, DC. 
O'Kelly, J. C., and W. G. Spiers. 1992. Effect of monensin on methane and heat productions of steers fed lucerne hay either ad libitum or at the rate of $250 \mathrm{~g} /$ hour. Aust. J. Agric. Res. 43:1789-1793.

Odongo, N. E., R. Bagg, G. Vessie, P. Dick, M. M. Or-Rashid, S. E. Hook, J. T. Gray, E. Kebreab, J. France, and B. W. McBride. 2007. Long-term effects of feeding monensin on methane production in lactating dairy cows. J. Dairy Sci. 90:1781-1788.

Rabiee, A. R., I. J. Lean, M. A. Stevenson, and M. T. Socha. 2010. Effects of feeding organic trace minerals on milk production and reproductive performance in lactating dairy cows: A meta-analysis. J. Dairy Sci. 93:4239-4251.

Rogers, J. A., and C. L. Davis. 1982. Rumen volatile fatty acid production and nutrient utilization in steers fed a diet supplemented with sodium bicarbonate and monensin. J. Dairy Sci. 65:944-952.

Ruiz, R., G. L. Albrecht, L. O. Tedeschi, G. Jarvis, J. B. Russell, and D. G. Fox. 2001. Effect of monensin on the performance and nitrogen utilization of lactating dairy cows consuming fresh forage. J. Dairy Sci. 84:1717-1727.

Rumpler, W. V., D. E. Johnson, and D. B. Bates. 1986. The effect of high dietary cation concentration on methanogenesis by steers fed diets with and without ionophores. J. Anim. Sci. 62:1737-1741.

Russell, J. B. 1987. A proposed mechanism of monensin action in inhibiting ruminal bacterial growth: Effects on ion flux and protonmotive force. J. Anim. Sci. 64:1519-1525.

Sauer, F. D., V. Fellner, R. Kinsman, J. K. Kramer, H. A. Jackson, A J. Lee, and S. Chen. 1998. Methane output and lactation response in Holstein cattle with monensin or unsaturated fat added to the diet. J. Anim. Sci. 76:906-914.
Terrin, N., C. H. Schmid, and J. Lau. 2005. In an empirical evaluation of the funnel plot, researchers could not visually identify publication bias. J. Clin. Epidemiol. 58:894-901.

Thornton, J. H., and F. N. Owens. 1981. Monensin supplementation and in vivo methane production by steers. J. Anim. Sci. 52:628 634.

US EPA. 2006. Global Anthropogenic Emissions of Non- $\mathrm{CO}_{2}$ Greenhouse Gases: 1990-2020. EPA Report 430-R-06-003. Accessed Jun. 12, 2012. http://www.epa.gov/methane/pdfs/Greenhouse GasReport.pdf.

Van Vugt, S. J., G. C. Waghorn, D. A. Clark, and S. L. Woodward. 2005. Impact of monensin on methane production and performance of cows fed forage diets. Proc. N.Z. Soc. Anim. Prod. 65:262-266.

van Zijderveld, S. M., W. J. J. Gerrits, J. Dijkstra, J. R. Newbold, R. B. A. Hulshof, and H. B. Perdok. 2011. Persistency of methane mitigation by dietary nitrate supplementation in dairy cows. J. Dairy Sci. 94:4028-4038.

Viechtbauer, W. 2010. Conducting meta-analysis in R with the metafor package. J. Stat. Softw. 36:1-48.

Waghorn, G. C., H. Clark, V. Taufa, and A. Cavanagh. 2008. Monensin controlled-release capsules for methane mitigation in pasturefed dairy cows. Aust. J. Exp. Agric. 48:65-68.

Waugh, C. D., D. A. Clark, G. C. Waghorn, and S. L. Woodward. 2005. Feeding maize silage to dairy cows: Implications for methane emissions. Proc. N.Z. Soc. Anim. Prod. 65:356-361.

Wedegaertner, T. C., and D. E. Johnson. 1983. Monensin effects on digestibility, methanogenesis and heat increment of a cracked cornsilage diet fed to steers. J. Anim. Sci. 57:168-177. 


\section{Appendix}

The $\mathrm{R}$ code used for the meta-analysis of the monensin effect on $\mathrm{CH}_{4}$ production in dairy cows is given below. Comments and code explanations are given by \#.

\#calculations of the explanatory variables centered on \#the means within the original data set namely " $\mathrm{d}$ " d $<-$ within $(d,\{$

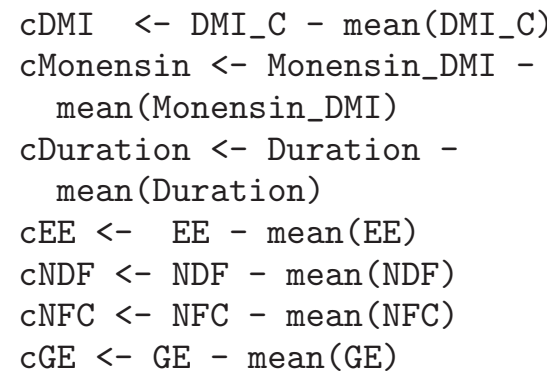

\#Compute standardized MD (SMD) for the forest plots dat2 <- escalc(m1i=CH4_M, sd1i=SE_M,

\#creating a forest plot using the SMD (using the \#"dat2" data)

$\mathrm{x} 11(11,7)$

forest (dat2\$yi, dat $2 \$ v i$, refline=0, cex $=1.2$, , slab = dat2\$Reference, xlim $=c(-60,25)$, at $=c(-6,-3,0,3$, $6)$, digits $=1$, ilab $=$ cbind (round (dat2\$CH4_C), round (dat2\$CH4_M)), ilab.xpos $=c(-30,-15))$

op <- $\operatorname{par}(\operatorname{cex}=1.2$, font $=2)$

text (c $(-30,-15), 12.5$, c ("CTL_CH4 (g/d)", "Monen_CH4 (g/d)"))

text $(-60,12.5$, "Author $(\mathrm{s})$ and Year", pos $=4)$

text (25, 12.5, "Standardized MD [95\% CI]", pos $=2)$

$\operatorname{par}(\mathrm{op})$ \#fit random effects model (using MD measures in the \#"dat" data)

fm $<-r m a(y i, v i$, data=dat)

summary $(\mathrm{fm})$

\#constructing the funnel plot

funnel ( $\mathrm{fm}$, main="Dairy cows")

\#conducting Egger's regression test for publication bias regtest (fm, predictor="sei")

\#fit the mixed-effect models including individual \#centered-explanatory variables

fm01 <- rma(yi, vi, data=dat, $\bmod =\sim \mathrm{cDMI})$ summary ( $f \mathrm{m01})$

fm02 <- rma(yi, vi, data=dat, $\bmod =\sim$ cMonen $\sin )$

summary ( $f \mathrm{m02}$ )

fm03 <- rma(yi, vi, data=dat, $\bmod =\sim$ cDuration)

summary ( $f \mathrm{m03}$ )

fm04 <- rma(yi, vi, data=dat, $\bmod =\sim \mathrm{cEE})$ summary ( $f \mathrm{m04})$

fm05 <- rma(yi, vi, data=dat, $\bmod =\sim \mathrm{cNDF})$ summary ( $f \mathrm{m05})$

$\mathrm{fm} 07<-\mathrm{rma}(\mathrm{yi}, \mathrm{vi}$, data $=$ dat, $\bmod =\sim \mathrm{cNFC})$ summary ( $f \mathrm{~m} 07$ )

fm09 <- rma(yi, vi, data=dat, $\bmod =\sim \mathrm{cGE})$ summary ( $f$ m09)

\#Obtaining summary statistics of the mixed-effect \#models need to be compared

fmL1 <- rma(yi, vi, data=dat, method="ML", $\bmod =\sim \mathrm{cDMI}+\mathrm{cEE}+\mathrm{cMonensin})$

summary ( $f \mathrm{~mL} 1)$

fmL2 <- rma(yi, vi, data=dat, method="ML", $\bmod =\sim$ cMonensin + cDMI )

summary ( $f \mathrm{~mL} 2)$

fmL3 <- rma(yi, vi, data=dat, method="ML", $\bmod =\sim \mathrm{cDMI}+\mathrm{cEE})$

summary ( $f \mathrm{~mL} 3$ )

fmL4 <- rma(yi, vi, data=dat, method="ML", $\bmod =\sim$ cMonensin $+\mathrm{cEE})$

summary ( $f m L 4)$

\#model comparison with log likelihood ratio tests anova ( $f m L 1, f m L 2)$

anova ( $f m L 1, f m L 3)$

anova ( $f m L 1, f m L 4)$

\# Final model fitting

fm3REML <- rma(yi, vi, data=dat, method="REML", mod $=\sim$ cDMI + cEE) summary ( $f$ m3REML)

\#funnel plot construction with the final model funnel (fm3REML, main="Dairy cows") 